\section{Crítica feminista al concepto "nini" (Ni trabaja ni estudia)}

\section{RESUMEN}

Se realiza una crítica desde corrientes feministas al concepto "nini" (ni trabaja ni estudia) a partir de los resultados obtenidos en la Primera encuesta sobre uso del tiempo en la gran Área Metropolitana de Costa Rica realizada en el 2011. El propósito es utilizar el indicador del tiempo para evidenciar brechas y desigualdades de género en la distribución, uso, intercambio y valor del tiempo en la organización de la vida cotidiana de la población de 12 a 35 años que reportó no trabajar ni estudiar.

Palabras Clave

Uso del tiempo; género; ninis; trabajo; trabajo no remunerado

\section{Feminist Critique of the Neet Concept (Not in Education, Employment, or Training)}

ABSTRACT

We criticize the concept of NEET (not in education, employment or training) using the results of the first Survey of Time Use in the Greater Metropolitan Area of Costa Rica of 2011. The objective is to use time as an indicator to express gaps and inequalities on the distribution, use, exchange, and value of time, that determine consequently the organization of everyday life on the population between 12 and 35 years old, who does not attend formal education and is neither employed.

KEY WoRDS

Use of time; gender; NEET; wagework; unwaged work
Costarricense. Socióloga por la Universidad de Costa Rica y Magíster en Gestión y Políticas Públicas por la Universidad de Chile. Directora del Instituto de Estudios de Género de la Universidad Estatal a Distancia de Costa Rica. Especialista y asesora en género en el Instituto Nacional de las Mujeres de Costa Rica. Especialista en transversalización de la perspectiva de género en instituciones públicas y de educación superior, en hostigamiento sexual y en estudios sobre uso del tiempo.

Correo electrónico: rchaves@uned.ac.cr.

Costarricense. Licenciada en sociología por la Universidad de Costa Rica. Doctorante del Instituto de Estudios Latinoamericano de la Freie Universität Berlin, Alemania. Investigadora del Instituto de Estudios de Género de la Universidad Estatal a Distancia de Costa Rica. Profesora de la Escuela de Sociología de la Universidad de Costa Rica. Ha trabajado en proyectos e investigaciones sobre transversalización de la perspectiva de género en instituciones de educación superior, investigaciones sobre uso del tiempo, corresponsabilidad social en el cuido, familia y feminismo decolonial.

Correo electrónico: alufefe@zedat.fu-berlin.de
Artículo recibido:

18 de febrero del 2016.

Evaluado:

13 de marzo del 2016.

Aceptado:

18 de abril del 2016.

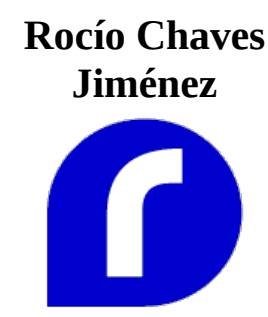

Ana Lucía

Fernández 


\section{Crítica feminista al concepto "nini"}

\section{Introducción}

Las personas jóvenes representan un segmento de la población significativamente amplio de la sociedad costarricense, de tal forma, se cuenta cada vez más con investigaciones concernientes a identificar y responder sobre sus particularidades desde diferentes enfoques, los cuales, se centran, fundamentalmente, en dos áreas de análisis: por un lado, las personas jóvenes en el ámbito de la educación y, por otro lado, a su inserción en el mercado de trabajo.

Sin embargo, desde la década de los ochenta en el Reino Unido surge el término NEET (not in education, employment or training, por sus siglas en inglés), a partir de un informe generado por la Unidad de Exclusión Social (Gutiérrez García; Martínez Martínez, \& Pacheco Trejo, 2014). Luego, es en España que se acuña el término en castellano "nini" en el 2008, después en México en el 2009 y a partir de ahí se empezó a extender por América Latina en el 2011 (Gutiérrez García; Martínez Martínez, \& Pacheco Trejo, 2014).

En ese sentido, de acuerdo a Tellez Velázco, "[...] el acrónimo nini fue acuñado por sociólogos españoles y hace referencia a jóvenes de entre 18 y 34 años cuyo rasgo distintivo es que ni tienen acceso a la educación ni al trabajo formal" (Téllez Velasco, 2011, p. 84).

Por su lado, Costa Rica en el 2011 realizó el Censo Nacional, en el cual se determinó que "existen un total de 201.870 jóvenes que no estudian ni trabajan, lo que corresponde al 19,3\% de la población etaria entre 12 y 24 años en ese año" (Contraloría General de la República de Costa Rica, 2014, p. 11). 
A partir de este resultado, numerosos diarios y noticieros periodísticos en el país (Barrantes, 2013; Chung Yajaira, 2012; Diario Extra, 2016; Repretel, 2015) se han abocado a tipificar este fenómeno a partir de nociones estereotipadas, que se identifican en algunas de las narraciones periodísticas,

Son jóvenes sin orientación, deprimidos, rebeldes y con exceso de tiempo libre en sus agendas. Se trata de personas que no cotizan para el régimen de IVM, que carecen de capacidad para obtener créditos bancarios y que se convierten en una especie de "parásitos sociales" (Diario Extra, 2016).

Por su parte, Mazzei (2012) desde el Programa Estado de la Nación ha realizado informes a la luz de los datos del Censo 2011, en donde se subdividió este grupo poblacional de jóvenes en cuatro grupos: Ios desempleados, quienes asisten a actividades de educación no formal; las mujeres con hijos que se dedican a actividades domésticas; y por último, el grupo más grande de esta población, quienes no registran ninguna actividad de estudio o trabajo, los cuales corresponden a 89694 jóvenes (Mazzei, 2012).

Es a partir de esta caracterización del Programa del Estado de la Nación que la prensa y algunos sectores gubernamentales y empresariales comenzaron a discutir el tema, para entrever estrategias que incorporen a este segmento poblacional en la sociedad costarricense.

Sin embargo, las nociones y opiniones que se desprenden a nivel académico, político y periodístico sobre los factores que causan la exclusión que viven estás personas jóvenes, no han sido suficientes para explicar el fenómeno. Por el contrario, se han realizado atribuciones de orden simplista, estereotipada y prejuiciosas sobre el fenómeno, y sobre la juventud.

Por lo tanto, el presente estudio procura profundizar en el análisis sobre las causas que afectan a este grupo poblacional a partir del uso del tiempo y actividades de la vida cotidiana identificadas en los datos generados de la Encuesta del Gran Área Metropolitana de Uso del Tiempo (EUT-GAM) del 2011.

Los datos revelan que si bien estas personas jóvenes no se encuentran insertas en el mercado de trabajo o en el sistema educativo formal, son las mujeres, quienes representan la mayor parte de esta población. Asimismo, se demuestra que ellas realizan intensas jornadas de trabajo no remunerado. 
Entonces, se analizará cómo la condición de género es un factor que puede determinar las oportunidades reales de acceso a un ejercicio ciudadano autónomo, con los derechos y los recursos materiales y simbólicos necesarios para vivir en bienestar.

Para el análisis se toma la definición de género que realiza Joan

Scott (2008),

El término "género" sugiere que las relaciones entre los sexos son un aspecto prioritario de la organización social (en lugar de derivar de las presiones económicas o demográficas); que los términos de identidad femenina y masculina están, en gran parte, determinados culturalmente ( $\mathrm{y}$ no son enteramente producidos por los individuos o las colectividades); y que las diferencias entre los sexos constituyen estructuras sociales jerárquicas que a la vez son constituidas por estas (pp. 45-46).

En este sentido, identificar y describir la situación de estas mujeres, es un paso hacia la crítica epistémica del concepto nini, con el objetivo de generar pistas para develar las causas de la discriminación que invisibiliza el trabajo no remunerado y que además, anula el reconocimiento de la economía de los cuidados como una forma de trabajo necesario para la reproducción de la sociedad.

Se entiende por economía de los cuidados a las actividades que se realizan en la esfera doméstica y para esta con el fin de asegurar la reproducción cotidiana. Asimismo, se establece el criterio de la tercera persona,

Este refiere a todas las actividades desarrolladas por y para los miembros del hogar que podrían ser delegadas a una tercera persona y que producen bienes o servicios mercantilizables (en el sentido de pasibles del intercambio mercantil). Se distingue de esta manera de las tareas de cuidado personal que cada persona realiza por sí misma (comer, lavarse) y actividades recreativas que no pueden delegarse (mirar televisión, escuchar música) (Rodríguez Enríquez, 2005, p. 6).

Se hace indispensable, por tanto, poner en evidencia y teorizar sobre el trabajo no remunerado que efectúan mayoritariamente las mujeres, como 
una posible arista para la realización de propuestas innovadoras para la política social y responder de acuerdo con las propias necesidades reales.

De tal forma, el presente artículo pretende determinar quiénes son y cómo utilizan el tiempo las personas jóvenes (entre 12 a 35 años) del Gran Área Metropolitana (GAM) que reportan no estudiar o no trabajar remuneradamente.

\section{Radiografía de la juventud en Costa Rica}

De acuerdo con el último informe elaborado por la Organización Internacional del Trabajo (OIT) sobre Juventud y Trabajo decente en América Latina, se puede constatar que "[...] la región aún se encuentra caracterizada como un continente joven, ya que el $69 \%$ son personas menores de 40 años" (Organización Internacional del Trabajo, 2014, p. 17).

En ese sentido, Costa Rica no escapa de esta realidad; tal como se identifica en los resultados del último Censo realizado en el 2011, "[...] la población joven es la más extensa, no obstante, la tasa de fecundidad ha bajado considerablemente a 1,8 hijos por mujer" (Instituto Nacional de Estadísticas y Censos, 2011a, p. 16).

Es importante considerar que la mayoría de la población joven se encuentra en el Gran Área Metropolitana, ya que "[...] el 72,8\% de la población reside en áreas urbanas" (Instituto Nacional de Estadísticas y Censos, 2011a, p. 20).

De acuerdo con el Consejo Nacional de la Política Pública de la Persona Joven y Fondo de Población de las Naciones Unidas (2010), Costa Rica ha asumido el compromiso de visibilizar y reconocer a esta población como sujetos de derechos. Por ende, el Estado y la sociedad costarricense tienen el compromiso de atender las necesidades específicas que enfrentan las personas jóvenes en contextos de cambios macroeconómicos de carácter global.

Si consideramos en una sola categoría los rangos de edad que van desde los 15 años y hasta los 34 años, según los estándares metodológicos del Censo 2011, se pueden identificar "1 526978 personas jóvenes, lo cual corresponde al 35,49\% de la población total del país" (Instituto Nacional de Estadísticas y Censos, 2011a, p. 19).

En ese sentido, los datos sobre la inserción en el sistema educativo formal muestran que el Estado costarricense en las últimas décadas no ha logrado la permanencia en el estudio de un porcentaje significativo de personas jóvenes, especialmente en secundaria, como bien lo demuestran las tasas de 
deserción en secundaria reportadas en los últimos datos del informe del Estado de la Educación elaborado por Castro Valverde (2013),

La exclusión educativa sigue siendo relevante en secundaria. La deserción inter-anual con un 11,2\% en el 2011 que representa un aumento respecto del $10,2 \%$ del 2010. En términos absolutos, el número de estudiantes excluidos aumentó de 35.503 a 39.032. En la educación académica diurna la cifra es un poco más baja con un 9,2\% pues la cifra global se ve influida por los altos índices de deserción en la modalidad nocturna con cifras de un 24,7\% para la académica nocturna y un 27,4\% para la técnica nocturna en el 2011 (p. 109).

Asimismo, los datos del último Censo del 2011, indican que "[...] solamente el $57.6 \%$ de la población de 5 a 29 años de edad asisten a la educación regular" (Instituto Nacional de Estadísticas y Censos, 2011a, p. 18).

Por otro lado, el acceso a un trabajo con o sin educación dista de ser una realidad para todos los casos, tal como se muestra en el informe de características económicas del Censo de 2011, en el cual se identifica que para la zona urbana, la población excluida de la fuerza de trabajo son mayoritariamente jóvenes, ya que la tasa de desempleo abierto en jóvenes con edades entre 15 a 19 años, 20 a 24 años y 25 a 29 años es de 15,65, 7,44 y 5,31 , respectivamente. Asimismo, se acrecientan las tasas de desempleo abierto en mujeres: en el rango de edad de 20 a 24 años la tasa es de 9,48 y en el rango de 25 a 29 años la tasa es de 6,08 (Instituto Nacional de Estadísticas y Censos, 2011b).

Llama la atención las grandes brechas en las tasas de ocupación y participación, puesto que son mucho menores en mujeres que en hombres. Por ejemplo, en las tasas de ocupación de personas entre 15 a 19 años, la tasa de mujeres es de 7,09 en comparación con la de los hombres que es de 21,22 (Instituto Nacional de Estadísticas y Censos, 2011b).

En el rango de edad de 20 a 24 años la tasa de mujeres es de 30,86 y para los hombres es de 70,60. En el rango de 25 a 29 años de edad la tasa de ocupación de mujeres es de 41,50 y la de los hombres es de 85,04. Por último, en el rango de edad entre 30 a 34 años la tasa de ocupación de mujeres es de 45,61 y la de los hombres es de 88,08 (Instituto Nacional de Estadísticas y Censos, 2011b). 
Lo mismo sucede con las tasas netas de participación: en el rango de edad de 15 a 19 años la tasa neta de participación de mujeres es de 8,18 en contraste con 25,38 en hombres. En el rango de 20 a 24 años de edad se acrecienta poco más que el doble puesto que la tasa de mujeres es de 34,09 y la de hombres es de 7,43. La tasa de participación de mujeres de 25 a 29 años es de 44,19 y la de hombres es de 89,38. Por último, la tasa de participación neta de personas entre 30 a 34 años es de 47,23 en mujeres y 92,18 en hombres (Instituto Nacional de Estadísticas y Censos, 2011b).

En relación con la fecundidad, las madres solteras y madres adolescentes, así como las responsabilidades familiares que se generan al tener hijos, se observa por ejemplo, que en la provincia de San José, existen distritos como Hospital $(2,08)$, San Sebastián $(1,96)$ o San José $(2,00)$ donde el promedio de hijos vivos por mujer es mayor que el promedio nacional (Zúñiga Villalobos \& Begurí Pagés, 2012). Asimismo, se reportan altos porcentajes de madres adolescentes entre 12 y 19 años, "[...] en el distrito de Hospital el porcentaje es de 7,63\%, en Pavas es 7,59\%, en San Sebastián es 6,47\% y en San José es de 6,69\%" (Zúñiga Villalobos \& Begurí Pagés, 2012, p. 38).

Además, se reportan también altos porcentajes de madres solteras: en el distrito de Mercedes de 19,55\%, en Hatillo es 18,28\%, Catedral y San Sebastián es de 16,79\% y en Pavas 16,21\% (Zúñiga Villalobos \& Begurí Pagés, 2012).

Por lo cual, la supuesta transición de terminar de estudiar para luego ir a trabajar $y$, posteriormente, formar una familia, no es tan lineal como lo adjudican algunas perspectivas sociológicas.

Por lo tanto, en el presente artículo se hace un recuento de las teorías feministas más relevantes que acompañaron los movimientos feministas de la primera, segunda y tercera ola. Con el objetivo de realizar un análisis sobre las tensiones entre la esfera pública y privada, la división sexual del trabajo y el patriarcado.

En ese sentido, desde el análisis feminista se aborda el fenómeno de las "ninis" en una sociedad católica, con valores conservadores y políticas liberales como lo es Costa Rica.

El objetivo, por lo tanto, es determinar las razones por las cuales existe una invisibilización de las condiciones de vida de las personas jóvenes que declaran no trabajar remuneradamente y que, además, reportan no estar insertos en el sistema educativo formal. Los datos demuestran que en su mayoría estas son mujeres. 


\section{Antecedentes sobre la valoración de la división sexual del trabajo $y$ de los roles de género en el feminismo}

Son muchos los estudios feministas elaborados en las últimas décadas, los cuales dan cuenta de las tres olas feministas de los siglos XVIII, XIX y XX, respectivamente. Los textos que se refieren a la primera ola del siglo XVIII, muestran tanto la historia de dicho movimiento así como los argumentos epistémicos que critican las bases ideológicas de la Modernidad. El principio de igualdad no reconoció a todas las personas por igual, y por el contrario, fueron las mujeres excluidas del proyecto revolucionario de la época (Cobo, de la Cruz, Volio, \& Zambrano, 2009; Paterman, 2002; Scott, 2008; Amorós, 1990; Benhabib, 1990).

Por lo tanto, el feminismo al igual que la sociología, encuentra sus orígenes en la consolidación de la Modernidad, sin embargo, a diferencia de la sociología, es en la llustración donde el feminismo encontrará el espacio para empezar a pensar la historia y a teorizar la política de forma distinta (Scott, 2008).

Son muchas las feministas que toman el recurso que utilizó Mary Wollstonercraft en su libro Vindication of the Right of Woman, reconocido como la primera obra feminista en el cual se enfatiza por primera vez que la desigualdad y exclusión de las mujeres se sostiene sobre la base de prejuicios y tradiciones de carácter social (Cobo et ál, 2009; Amorós, 1990; Benhabib, 1990). Este texto fue utilizado para debatir las ideas ilustradas de Rousseau sobre la educación de las mujeres. El gran tratado de educación del siglo XVIII, Emilio o la Educación, específicamente en el capítulo V, el cual hace referencia al personaje de Sofía como la gran metáfora, "[...] para explicar lo que él denomina la verdadera naturaleza de la mujer, que no es otra cosa que el nuevo modelo de normatividad femenina que tan funcional es a la nueva clase política emergente: la burguesía" (Cobo et ál, 2009, p. 20). Sofía es la metáfora del ideal de la figura femenina del discurso liberal burgués que sueña y representa en ella, la mujer de esta nueva sociedad, basando sus argumentos en la ontología de la mujer para justificar la naturaleza inferior de la mujer y por ende, su subordinación.

Sin embargo, dos puntos importantes de este debate son los que interesan rescatar: por un lado, la consolidación de los nuevos valores que sustentan la ideología de la Modernidad basada en la razón, la cual viene a sustituir el predominio de la religión para dar paso al gobierno de sí mismo; por otro lado, la exclusión de las mujeres del proyecto emancipatorio.

Ahora bien, dicha lógica de subordinación de las mujeres se sustenta en una dinámica que consolida los roles sociales de género desde la base del surgimiento del Estado Nación, recreando una apología burguesa de las relaciones sociales basadas en justificaciones de orden natural, para 
designar quiénes pertenecen exclusivamente al mundo de lo privado y quiénes tienen potestad en ambas esferas (la pública y la privada).

En ese sentido, en la esfera de lo privado que corresponde a la familia, subsiste fuera de la esfera de la justicia. Por lo tanto, la mujer es quien queda relegada de dicha esfera pública generando así desde los inicios de la Modernidad, las bases que niegan el reconocimiento de la autonomía femenina, y negando además, la construcción social en las relaciones de género (Benhabib, 1990).

Este hecho histórico lo señaló Carole Pateman, cuando afirma que la teoría política de Hobbes no solo consolidó el contrato social, el cual constituye las bases de los derechos políticos y de la ley civil para la consolidación de los Estados, sino que también afianza el contrato sexual, en el cual se constituye el poder político masculino como derecho conyugal (Pateman, 1989).

La justicia entonces se edificará en la vida pública, la cual comprende una serie de deberes y derechos que mediarán el orden social entre los hombres. Sin embargo, lo que importa señalar en esta relación, es que el nuevo espacio moderno que constituye la normalización del espacio público entre individuos, "[...] de lo que se trata es de que en este universo la experiencia de la mujer moderna no tiene lugar" (Benhabib, 1990, p. 9).

Por lo tanto, la formación de la familia moderna tiene connotaciones importantes para este análisis. Según Theron (2007), la constitución de la familia se encuentra regida por tres dimensiones: el patriarcado, el orden sexual y la fecundidad. Se define institución social como "[...] estructuras de normas donde se fija y mantiene un juego de roles sociales; en este sentido, también es posible verlas como un tipo de equilibrio social entre poder y beneficios" (Theron, 2007, 32). La familia, entonces, es una institución definida por el parentesco que se basa en acciones y estrategias individuales o familiares fijadas por normas sociales, permitiendo así la continuidad, reproducción y reafirmación de grupos sociales (Gil Martínez de Escobar, 2006).

Entonces, las acciones y estrategias que se constituyen alrededor de la familia se mantienen en parte, por medio de un sistema de dominación patriarcal, que es una forma de organización política, económica, religiosa y social basada en la superioridad de los hombres sobre las mujeres, la cual establece ejercicios de poder simbólicos y materiales con el objetivo de establecer jerarquías (Cobo et ál, 2009). El sistema patriarcal como mecanismo de dominación se establece, fundamentalmente, sobre una base ideológica de carácter antropocéntrico, la cual constituye el mundo a imagen del hombre como sexo dominante, y crea de esta manera el privilegio, al relativizar su propia experiencia. 
Así, la familia heterosexual nuclear moderna se consolida a través de los roles sociales de género, en donde los hombres detentadores del espacio público, son socializados para administrar las relaciones familiares y la propiedad familiar (la prole como objeto de legitimación de la reproducción de su propia génesis), dador y ejecutor de la palabra, de la orientación y de los proyectos familiares como jefe de familia. Por el otro lado, las mujeres son relegadas al servicio de los placeres del hombre, del proyecto de vida del esposo, y al cuidado de la prole y del hogar (Cobo et ál, 2009).

En esa línea, Benhabib explica cómo las mujeres dentro de la esfera privada son mantenidas en un espacio atemporal y ahistórico, repitiendo cíclicamente tareas de nutrición y reproducción de manera indefinida (Benhabib, 1990). La división de espacios supone la asunción de privilegios, puesto que el derecho ejercido en la esfera pública por los hombres se traduce en privilegio si se le compara con la negación de derechos a la que fueron sometidas las mujeres en este proceso histórico.

Por lo tanto, con el florecimiento de la Modernidad se sentaron las bases de la división sexual del trabajo moderno, donde por un lado a los hombres se les concedió el ejercicio de la ciudadanía, y por el otro, la vida doméstica se le otorgó a las mujeres (Cobo et ál, 2009). La democracia se forja y se mantiene a través de instituciones y estructuras que legitiman y mantienen el núcleo fundamental de su propia reproducción social, la cual se erige en la familia nuclear heterosexual patriarcal a través de la división sexual del trabajo.

Valcárcel (2011) describe desde el derecho, cómo son excluidas las mujeres,

En las nuevas codificaciones civiles, con la ayuda fundamental del modelo del derecho romano, la minoría de edad perpetua para las mujeres quedaba consagrada. Eran consideradas hijas o madres en poder de sus padres, esposos e incluso sus hijos. No tenían derecho a administrar su propiedad, fijar o abandonar su domicilio, ejercer la patria potestad, mantener una profesión o emplearse sin permiso, rechazar a un padre o marido violentos. La obediencia, el respeto, la abnegación y el sacrificio quedaban fijadas como sus virtudes obligatorias. El nuevo derecho penal fijó para ellas delitos específicos que, como el adulterio y el aborto, consagraban que sus cuerpos no les pertenecían. A todo efecto ninguna era dueña de sí misma, luego todas carecían de lo que la ciudadanía aseguraba, la libertad (p. 13). 
Entonces, desde la Modernidad el reconocimiento y por ende, el valor que se le adjudicó a la asignación de roles de género que se realizaba dentro y fuera del núcleo familiar, fue desigual. El trabajo que realizan las mujeres en la esfera privada, no es reconocido como tal, y sin embargo, es el que posibilita las tareas productivas de la esfera pública.

Por lo tanto, esta ideologización del valor del trabajo en la esfera pública por encima del trabajo reproductivo y de los cuidados en lo privado, caló en las nociones tradicionales de los políticos, científicos y médicos, generando así los cimientos de las instituciones sociales, las cuales se erigieron arraigadas con base en dicha lógica de diferenciación.

Asimismo, ya para el siglo XIX los argumentos para diferenciar a hombres y mujeres también tuvieron su forma de reargumentarse gracias a filósofos de la época, entre quienes destacan Hegel, Schopenhauer, Kierkegaard, Nietzsche (Valcárcel, 2001). Ellos a través de su impronta misógina romántica objetaron en contra de la segunda ola del feminismo (Valcárcel, 2001).

Esta nueva etapa para el feminismo surge en el siglo XIX con el movimiento sufragista. Este se genera a partir de un hito histórico que fue la Declaración de Seneca Falls en 1948 en Estado Unidos. Aquí un grupo de mujeres exigieron los mismos derechos formulados desde la llustración por los hombres (Cobo et ál, 2009). Aunque el movimiento se organizó alrededor del derecho al voto, primeramente en sociedades industriales de religión protestante, también la base de sus reivindicaciones fueron, "[...] el derecho a la propiedad, a la educación, el acceso a las profesiones o a la libertad para organizarse o hablar en público" (Cobo et ál, 2009, p. 22).

En este momento, las luchas de las mujeres sufragistas se enfatizaron en ampliar sus reivindicaciones políticas en términos de igualdad y libertad, específicamente en cuanto al voto y la educación (Cobo et ál, 2009; Valcárcel, 2001).

Después de la Segunda Guerra Mundial, en casi todo el mundo las mujeres habían alcanzado el derecho al sufragio. Sin embargo, cuando los hombres volvieron de la guerra, las mujeres no fueron utilizadas más en los espacios y trabajos de hombres, que se requirió cuando estos tomaron las armas. Por el contrario, una nueva "mística de feminidad" como lo llamo Betty Friedam (2009), surgió a partir de la década de los cincuenta, cuando se devolvieron al hogar a las mujeres, o a trabajos para la diversificación de la producción, excluyendo de esta manera nuevamente, a las mujeres de los espacios productivos que habían ejercido durante el periodo de guerras. 
De esta forma, los recién adquiridos derechos en términos de educación y sufragio para las mujeres, no produjeron un cambio en la tradicional división sexual del trabajo. Por el contrario, se estimuló, desde los gobiernos y los medios de comunicación, el regreso de la mujer al hogar, pero ya no sobre la base de fundamentaciones naturalistas o esencialistas, sino como un discurso que promovía que la mujer, ahora educada y con derechos, voluntariamente regresara a la familia (Valcárcel, 2001). Desde una economía liberal capitalista, la familia ya no era reconocida como el centro de reproducción sino del consumo (Valcárcel, 2001).

Por lo tanto, en la década de los setentas el descontento general de los movimientos de mujeres, tuvo más que ver con el entramado en las relaciones de poder entre hombres y mujeres, que con el acceso al espacio público en términos de reivindicaciones como la educación o el sufragio. Surge el patriarcado como conceptualización del derrotero al que había que desmontar. Entendido como "[...] el término elegido para significar el orden socio-moral y político que mantenía y perpetuaba la jerarquía masculina. Un orden social, económico, ideológico que se auto-reproducía por sus propias prácticas de apoyo con independencia de los derechos recientemente adquiridos" (Varcárcel, 2001, p. 23).

Así se inaugura la tercera ola feminista en el siglo XX, con la frase célebre de Kate Millet (1995): "lo personal es político". La idea central que sostiene Millet (1995) es que la exclusión de las mujeres no viene dada solamente a través de la esfera pública en tanto que discursos e instituciones sociales y económicas; sino que la desigualdad y subordinación se generan a través de prácticas culturales más profundas que se originan no solo en la esfera pública, sino también en la familia. Las raíces del patriarcado se encuentran en las relaciones de pareja, en las tareas de los cuidados y en todas las actividades relacionadas con la familia y el ámbito de reproducción de la vida, que realizan las mujeres de forma gratuita (Cobo et ál, 2009).

Por lo tanto, como afirma Cobo et ál (2009),

La familia no es un espacio de afecto y cuidados, presidido por la simetría entre varones y mujeres sino una institución patriarcal en la que se asienta la división sexual del trabajo, se esconden las relaciones de poder entre hombres y mujeres detrás del amor y de los cuidados y en muchos casos se desarrolla la violencia y el abuso sexual masculino contra las mujeres. $Y$ todas estas prácticas no son aspectos íntimos de las parejas o de las familias, como se ha tendido a contar, sino relaciones políticas basadas en la explotación y subordinación de las mujeres (p. 25). 
Con esta nueva forma de entrever las relaciones desiguales de poder entre hombres y mujeres, es que las feministas radicales reflexionaron sobre "[...] la política sexual del patriarcado como una política que actúa en lo privado e íntimo y en lo público y lo político" (Cobo et ál, 2009,p. 25). En ese sentido, el objetivo común por alcanzar es derrotar al patriarcado desde sus cimientos. De esta manera, es que al trabajo de los cuidados y al trabajo doméstico se les comienza a dar visibilidad, como un tema de importancia no solo para la reivindicación y ensanchamiento de la democracia para las mujeres, sino como un tema competente a la economía, puesto que el trabajo para el mercado necesita de la reproducción de la vida diaria para poder existir. Este es un trabajo efectuado por las mujeres de forma gratuita a través de la historia, pero que no se había visibilizado como tal.

En este sentido, es que surgen más adelante a finales del siglo $X X$ y principios del siglo XXI, esfuerzos concernientes a dar visibilidad al trabajo que realizan las mujeres dentro de los hogares, por medio de técnicas novedosas, como es el caso de las Encuestas de Uso de Tiempo a nivel global. Esta es una estrategia desarrollada por economistas y estadísticas feministas para convertir lo invisible en visible, a partir del uso del tiempo como un indicador que mide las desigualdades en términos de bienestar.

Aguirre \& Ferrari (2013), señalan que los inicios de las encuestas de uso del tiempo se desarrollaron en el último tercio del siglo $X X$ en los países más desarrollados de Europa, puesto que existía una necesidad de la industria del ocio y de los medios de comunicación por conocer las actividades diarias de las personas.

Por otro lado, desde los movimientos feministas y especialistas en el género, tuvieron como objetivo visibilizar el trabajo no remunerado a través de este instrumento, "[...] destacando la importancia de la medición del trabajo doméstico en los hogares como aporte sustantivo a las economías de los países industrializados" (Aguirre \& Ferrari, 2013, p. 14).

Actualmente, el debate sobre el trabajo no remunerado desde los movimientos feministas, se centran en señalar que el trabajo de los cuidados y doméstico no se rige por el derecho, sino a través de la disponibilidad de otra persona, generalmente una mujer, en el cual media una relación informal y gratuita, en la mayoría de las veces. En contraposición, la otra opción de acceso al cuidado pasa por una relación mercantil, de esta manera, el cuidado es visto como un recurso de consumo, más que como un derecho.

Esquivel (2011) explica cómo desde la economía se explica la capacidad de consumo de los hogares, por medio de los ingresos para poder medir el bienestar. Sin embargo, desde la economía que se ha evocado a problematizar el trabajo no remunerado dentro de los hogares, señala que el 
consumo de los hogares se amplía gracias al trabajo doméstico y de los cuidados pues estos complementan a los ingresos (Esquivel, 2011).

Por lo tanto, desde el feminismo de la igualdad se reflexiona sobre la importancia de la reproducción social a través del trabajo de los cuidados que se ha realizado a lo interno de las familias, y se señala la ausencia por parte de los regímenes de bienestar de los Estados, al no considerar el cuidado como un derecho universal en términos de cuidar, ser cuidado y a cuidarse (Aguirre \& Ferrari, 2013).

En ese sentido, se refiere a no considerar solamente la provisión de cuidados a poblaciones particulares como por ejemplo niños, niñas, adultos mayores o personas enfermas. Asimismo, tener en cuenta también a las personas que proveen cuidados, quienes en su mayoría son mujeres, como lo demuestran las encuestas de uso del tiempo (Esquivel, 2011).

Por lo tanto, las exigencias hacia los Estados son señaladas por Aguirre \& Ferrari (2013):

No debe ser una prestación de apoyo dirigida a las mujeres que buscan trabajar sino un derecho a recibir cuidados dignos, especialmente para las personas dependientes (niños y niñas, mayores, discapacitados y discapacitadas) y un derecho a realizar el cuidado en condiciones adecuadas para las personas que cuidan. Esos derechos, tanto de la persona cuidada como del cuidador o la cuidadora, deben ser normados, regulados y protegidos por el Estado, sin perjuicio de reconocer las obligaciones de los sujetos que deben proveer cuidados, los miembros de la pareja en relación a sus hijos y de los hijos varones y mujeres en relación a los ascendientes en situación de dependencia. Obligaciones que entran en tensión con el derecho a optar entre cuidar y no cuidar (p. 6).

Sin embargo, feministas más radicales como por ejemplo Federici (2013), afirman que el capitalismo es quien "[...] ha producido la privatización de la reproducción" (p. 256). En contraposición, señala que es en el trabajo a lo interno de los hogares donde se encuentran los cimientos de la economía. Entonces, las mujeres deben reclamar ese espacio como "[...] centro de la vida colectiva, de una vida transversal a múltiples personas y formas de cooperación, que proporcione seguridad sin aislamiento y sin obsesión, que permita el intercambio y la circulación de las posesiones comunitarias, y 
sobre todo que cree los cimientos para el desarrollo de nuevas formas colectivas de reproducción" (Federici, 2013, p. 257).

Asimismo, investigadoras como Martínez (2009) se han abocado a estudiar las relaciones entre los regímenes de bienestar y los órdenes de género, con el objetivo de visualizar desigualdades entre hombres y mujeres, en términos de la articulación y entretejido de ambos sistemas en la vida cotidiana de las personas. Desde este punto de vista, Martínez Franzoni \& Voorend (2009) afirman cómo las sociedades se encuentran "[...] estructuradas en torno al género como organizador jerárquico de diferencias basadas en el sexo de las personas. A la vez, reconoce que el patriarcado no existe desprovisto de acuerdos sociales y de Estados que, al regular, reproducen o vulneran dicha estratificación" (p. 17).

Por lo tanto, como bien lo señala Cobo et ál (2009), existen dos presupuestos que considerar al analizar el fenómeno del trabajo de cuidado y doméstico que realizan las mujeres dentro de la esfera privada. Primero, que las construcciones sociales y culturales alrededor de la división sexual del trabajo y de la exaltación a los deberes de la "femineidad" esencialista, reducen tanto la autonomía como la libertad de las mujeres (Cobo et ál, 2009). Se representa en el acceso político y económico en la esfera pública, con las consecuencias que esto implica, en términos de oportunidades, recursos y participación. Por otro lado, entender que las desigualdades de género no solo se encuentran presentes en la esfera pública, sino que también existe una ideología dominante androcéntrica y patriarcal que penetra la organización de la vida a lo interno de los hogares, y estructura las relaciones desiguales entre hombres y mujeres.

Por último, el trabajo de los cuidados y el trabajo doméstico a lo interno de los hogares, es un tema que el feminismo ha estado problematizando desde hace mucho tiempo, porque encierra puntos de inflexión sobre la condición de las mujeres, las desigualdades y el trabajo que no se visibiliza como tal. En este sentido, Carrasco (2011) señala que la tarea de lo que ella identifica como economía feminista, es la de integrar en los análisis "[...] todos los trabajos necesarios para la subsistencia, el bienestar y la reproducción social y tenga como principal objetivo las condiciones de vida de las personas" ( $p$. 208).

\section{La Encuesta de Uso del Tiempo en la Gran Área Metropolitana de Costa Rica}

La Encuesta sobre Uso del Tiempo en la Gran Área Metropolitana de Costa Rica (EUT-GAM, 2011) tiene como objetivo brindar a la sociedad costarricense la información recopilada sobre la contribución económica que 
realizan hombres y mujeres, por medio del trabajo no remunerado (Instituto Nacional de las Mujeres; Universidad Nacional. Instituto de Estudios en Población e Instituto Nacional de Estadísticas y Censos, 2012). La encuesta se realizó durante los meses de marzo y abril del 2011.

La población de estudio fueron las personas mayores de 12 años, residentes habituales de viviendas particulares en la Gran Área Metropolitana (GAM) de Costa Rica, la cual incluye cuatro provincias (Cartago, San José, Heredia y Alajuela), 24 cantones y 110 distritos; en la GAM se concentran un poco más del $50 \%$ de la población del país, y agrupa al 51,2\% de los hogares del país (Instituto Nacional de las Mujeres; Universidad Nacional, Instituto de Estudios en Población e Instituto Nacional de Estadísticas y Censos, 2012).

La encuesta comprendió tres cuestionarios distintos, uno de ellos relacionado con aspectos sobre las viviendas y los hogares aplicado a las personas identificadas como informantes clave (Cuestionario 1), otro cuestionario sobre ayudas domésticas hacia otros hogares pagado o no pagado, el cual debía ser contestado también por la persona informante clave (Cuestionario 2), y por último, un cuestionario sobre uso del tiempo, donde el informante era cada una de las personas mayores de 12 años que habitaban en el hogar (Cuestionario 3).

Asimismo, cabe señalar que la muestra utilizada en la EUT-GAM del 2011 fue proporcionada por la Unidad de Muestreo del Instituto Nacional de Estadísticas y Censos (INEC), la cual, además, fue utilizada para la Encuesta de Hogares de Propósitos Múltiples 2009 (Instituto Nacional de las Mujeres; Universidad Nacional, Instituto de Estudios en Población, e Instituto Nacional de Estadísticas y Censos, 2012). Dicha muestra es de tipo probabilística de áreas estratificadas, y le fueron aplicados los procedimientos de factores de expansión y estimación de la Encuesta Nacional de Hogares (ENAHO) del 2009 (Instituto Nacional de las Mujeres; Universidad Nacional, Instituto de Estudios en Población, e Instituto Nacional de Estadísticas y Censos, 2012).

La tasa de respuesta para el Cuestionario 1 fue del $88,4 \%$ de un total de 2636 viviendas y la del Cuestionario 3 fue de $81,11 \%$ de un total de 6378 informantes mayores de 12 años o más, se recogieron 5123 cuestionarios completos (Instituto Nacional de las Mujeres; Universidad Nacional, Instituto de Estudios en Población, e Instituto Nacional de Estadísticas y Censos, 2012).

Finalmente, para identificar a las personas jóvenes que reportan no trabajar ni estudiar, se utilizó el Cuestionario 3, ya que este recoge la información sobre el uso del tiempo de todas las personas habitantes del hogar mayores de 12 años, con el objetivo de realizar una caracterización sobre estas personas, utilizando la variable tiempo como indicador de medida para el análisis de las diferentes actividades determinadas en el cuestionario. 


\section{Radiografía de las personas "ninis" de la Gran Área Metropolitana de Costa Rica.}

De acuerdo con los datos recogidos en la Encuesta de Uso del Tiempo de la GAM, se puede constatar un total de 54759 personas jóvenes entre 12 y 35 años que reportaron no trabajar remuneradamente ni estudiar. De este total, el $87 \%$ son mujeres y el $13 \%$ son hombres, tal y como se muestra en la tabla 1.

Tabla 1

EUT-GAM. Personas "ninis" por sexo y edad (2011)

\begin{tabular}{lcc}
\hline Sexo & Absoluto & Relativo \\
\hline Hombre & 7145 & 13 \\
\hline Mujer & 47614 & 87 \\
\hline Total & 54759 & 100 \\
\hline $\begin{array}{l}\text { Elaboración propia a partir de datos de la Encuesta sobre uso del tiempo } \\
\text { del Gran Área Metropolitana (EUT-GAM), } 2011\end{array}$
\end{tabular}

Asimismo, para profundizar en el análisis se establecieron dos rangos de edad: de 12 a 24 años y de 25 a 35 años. En el primer rango de edad, se identificó que el $75,8 \%$ son mujeres. Para el segundo rango, el porcentaje de mujeres acrecienta en un $97,1 \%$.

Tabla 2

EUT-GAM. Personas "ninis" por sexo y rangos de edad (2011)

\begin{tabular}{|c|c|c|c|c|c|c|}
\hline \multirow{2}{*}{ Sexo } & Absoluto & Relativo & Absoluto & Relativo & Absoluto & Relativo \\
\hline & \multicolumn{2}{|c|}{12 a 24 años } & \multicolumn{2}{|c|}{25 a 35 años } & \multicolumn{2}{|c|}{ Total } \\
\hline Hombre & 6319 & 24,2 & 826 & 2,9 & 7145 & 13,0 \\
\hline Mujer & 19780 & 75,8 & 27834 & 97,1 & 47614 & 87,0 \\
\hline Total & 26099 & 100 & 28660 & 100 & 54759 & 100 \\
\hline
\end{tabular}

Por lo tanto, existe una fuerte feminización de la población considerada "nini", lo cual puede ser visto como un posible indicador que ilustra las diferencias por sexo en términos de acceso a oportunidades, recursos y mejores condiciones de vida. Comprendiendo que estas personas, en su mayoría mujeres se encuentran por fuera del mercado y de la educación (Cobo et ál, 2009). 
Las mujeres al no estar dentro de la educación formal o en algún tipo de trabajo para el mercado, son excluidas del ámbito público que es donde "[...] se genera todo el trabajo relacionado con la producción y el intercambio monetario" (Cobo et ál, 2009, p. 175).

De tal forma, existe una valoración distinta entre el ámbito público o trabajo para el mercado y el ámbito doméstico o privado. Con las cifras sobre personas "ninis" de la EUTGAM se puede evidenciar la reproducción tradicional de roles de género y división sexual del trabajo. El trabajo no remunerado, al desarrollarse dentro de la esfera privada, no es identificado como trabajo mercantilizado $y$, en consecuencia, es invisibilizado y subvalorado económica y socialmente. Por otro lado, se identificó el estado conyugal de estas personas, donde se evidencia que la mayoría de las mujeres están casadas o conviven en unión libre (64\%). En menor medida, mujeres solteras $(27,6 \%)$ o divorciadas, separadas o viudas $(8,4 \%)$. En contraposición, el porcentaje de los hombres casados o que viven en unión libre es de 11,6\%; y el porcentaje de hombre "ninis" solteros es de $88,4 \%$.

Tabla 3

EUT-GAM. Personas “ninis" por sexo y estado conyugal (2011)

\begin{tabular}{lcccccc}
\hline Estado Conyugal & Hombre & $\%$ & Mujer & $\%$ & Total & \\
\hline $\begin{array}{l}\text { Unidas (os) y } \\
\text { casadas(os) }\end{array}$ & 832 & 11,6 & 30458 & 64,0 & 31290 & 57,1 \\
\hline $\begin{array}{l}\text { Divorciadas(os),separ } \\
\text { adas (os), viudas (os) }\end{array}$ & 0 & 0 & 4017 & 8,4 & 4017 & 7,3 \\
\hline Solteras (os) & 6313 & 88,4 & 13139 & 27,6 & 19452 & 35,5 \\
\hline Total & 7145 & 100 & 47614 & 100 & 54759 & 100 \\
\hline
\end{tabular}

Elaboración propia a partir de datos de la Encuesta sobre uso del tiempo del Gran Área Metropolitana (EUT-GAM), 2011.

En ese sentido, se retoma una de las hipótesis de Martínez Franzoni \& Voorend (2009), en la cual afirman que,

Las familias se insertan en los regímenes a través de una marcada división sexual del trabajo. La mayor parte del trabajo no remunerado, tanto de trabajo doméstico como de cuidados, se encuentra en manos de mujeres, aun cuando éstas hayan ingresado en el mercado laboral y cuenten con capacidad de delegar tal trabajo, por ejemplo, a trabajadoras domésticas remunerado (146).

De acuerdo con esta investigación sobre los regímenes de bienestar y ordenes de género, en Costa Rica la división sexual del trabajo es bastante 
pronunciada ya que "[...] 7 de cada 10 personas encuestadas con trabajo remunerado son hombres y sólo 3 son mujeres. Además, en el total de mujeres referidas, sólo 2 de cada 10 mujeres tienen trabajo remunerado" (Martínez Franzoni \& Voorend, 2009, p. 152).

Asimismo, Martínez Franzoni \& Voorend (2009) afirman que al identificar el tiempo dedicado al trabajo no remunerado, se constata que la participación de los hombres es casi nula. Estos datos también se corroboran con las pocas horas que dedican los hombres ninis a trabajos domésticos y de cuidado, en comparación con las mujeres.

El estudio de Sandoval Carvajal \& González Vega (2015) muestra que la tasa de participación femenina creció del 20\% en 1970 al 45,2\% para el 2013. Sin embargo, "[...] la incorporación de las mujeres al mercado laboral ha ocurrido en condiciones menos favorables que las de los hombres. Así, ellas han tenido mayores tasas de desempleo abierto: para 2013, según la Encuesta Nacional de Hogares, la tasa para los hombres era de $7 \%$, mientras que para las mujeres, de 11 por ciento" (Sandoval Carvajal \& González Vega, 2015, p. 692).

Por lo tanto, los resultados sobre uso del tiempo en la investigación de Martínez Franzoni \& Voorend (2009) y de Sandoval Carvajal \& González Vega (2015) congenian con las cifras sobre ninis de la EUT-GAM. En la GAM todavía hay una amplia población femenina dedicada, exclusivamente, al trabajo no remunerado, y al no ser contabilizado en la esfera pública, terminan siendo invisibilizadas, lo cual hace que se reproduzcan estereotipos sobre las actividades que realizan la población considerada como "nini", ya que se parte del supuesto que no realizan ninguna actividad productiva.

Por otro lado, en la tabla 4 se muestra la distribución horaria del trabajo doméstico que realizan las personas "ninis" por semana, en donde se puede observar que más de la mitad de las mujeres $(53,8 \%)$, tienen jornadas iguales o mayores a las 50 horas semanales. Estas son más horas de trabajo que las asignadas a una jornada de tiempo completo en el mercado. En contraposición, solo el $0,5 \%$ de los hombres se encuentran en esta misma condición. La brecha de género en contra de las mujeres es dramática.

Tabla 4

EUT-GAM. Personas "ninis" por sexo por horas de jornada doméstica (2011)

\begin{tabular}{lcccccc}
\hline $\begin{array}{l}\text { Jornada semanal } \\
\text { Trabajo doméstico }\end{array}$ & Hombre & $\%$ & Mujer & $\%$ & Total & $\%$ \\
\hline Menos de 15 horas & 3519 & 6,40 & 2942 & 5,40 & 6461 & 11,80 \\
\hline
\end{tabular}




\begin{tabular}{lcccccc}
\hline $\mathbf{1 5}$ a 34 horas & 2003 & 3,70 & 7079 & 12,90 & 9082 & 16,60 \\
\hline $\mathbf{3 5}$ a $\mathbf{5 0}$ horas & 1354 & 2,50 & 8160 & 14,90 & 9514 & 17,40 \\
\hline $\mathbf{5 0}$ y más horas & 269 & 0,50 & 29433 & 53,80 & 29702 & 54,20 \\
\hline Total & 7145 & 13,00 & 47614 & 87,00 & 54759 & 100,00 \\
\hline
\end{tabular}

Elaboración propia a partir de datos de la Encuesta sobre uso del tiempo del Gran Área Metropolitana (EUT-GAM), 2011.

De esta forma, se puede ver como el trabajo es considerado como tal, en la medida que existe una remuneración mercantil en la relación social. Sin embargo, al contabilizar el tiempo de las mujeres en los trabajos doméstico y de cuido, se puede equiparar en una misma medida (en este caso el tiempo), con el trabajo para el mercado. En este sentido, se puede identificar que las mujeres que aseguran no trabajar para el mercado, ni estudiar sean personas desocupadas o inactivas. El tema aquí es entender que el valor del trabajo para el mercado y el valor del trabajo del cuidado de la vida, no tienen el mismo valor desde un punto de vista mercantil y capitalista. Esta noción del trabajo se encuentra asociada a los valores que desde la llustración se han venido edificando como la única o mejor forma de organización social, en donde se le da reconocimiento al valor de un trabajo sobre el otro. Estas diferencias encuentran sus cimientos en las relaciones de poder asimétricas promovidas por el patriarcado, y la división sexual del trabajo es una de ellas.

El caso de las mujeres "ninis" en Costa Rica, es un claro ejemplo de que estas mujeres se encuentran en espacios de reproducción del discurso tradicional de la familia nuclear patriarcal, en donde la mujer por su condición de mujer cuida a otras personas y realiza trabajo doméstico, como un patrón de su feminidad y por ende, del rol tradicional de género que debe asumir.

Asimismo, cuando se analizan los datos generales de la EUT GAM, las brechas de género en términos de tiempo son evidentes. Por ejemplo, según Sandoval Carvajal \& González Vega (2015), en la suma de trabajo remunerado y no remunerado, se puede constatar que la carga de las mujeres es de 72:56 horas semanales, mientras los hombres de 65:47. Y además, se evidencia que, "[...] sin importar su condición, edad, nivel educativo, relación de parentesco, estado conyugal o actividad, las cargas globales de las mujeres son siempre superiores a las de los hombres" (Sandoval Carvajal \& González Vega, 2015, p. 694).

En ese sentido, en Costa Rica todavía predomina la sumisión de las mujeres al espacio privado y de este tipo de organización social, puesto que al ser un Estado confesional, establecido así en el artículo número 75 de la Constitución Política del país, los discursos institucionales dentro del Estado y los discursos religiosos promueven desde su constitución prácticas 
culturales que legitiman la división sexual del trabajo, como algo natural, y como algo deseable para la organización social del país.

Es cierto que no todas las mujeres del país se encuentran en esta condición actualmente; sin embargo, el caso de las mujeres "ninis" es un ejemplo que demuestra que para el sostenimiento del régimen de bienestar costarricense, es necesaria la reproducción de este tipo de discursos tradicionales. Desde una mirada económica, el trabajo que las mujeres efectúan se hace de manera gratuita, lo que significa menos cargas monetarias para el Estado, y para el mercado.

Al mismo tiempo, la explotación de las mujeres tanto en la esfera privada como en la pública del trabajo no remunerado, genera consecuencias insospechables para sus vidas. Al estar confinadas en la esfera privada y depender económicamente del cónyuge, quedan al margen del acceso a la ciudadanía (Kant, 1784). En ese sentido, el tema de la dependencia económica que acarrea argumentos pertinentes al acceso al bienestar, en tanto que herramientas, recursos y oportunidades no es polemizado, y más bien se naturaliza desde algunos sectores de la población como algo deseado, cuando lo que realmente sucede es la infantilización de estas mujeres, en tanto que la sociedad no le está proveyendo de herramientas, recursos y oportunidades para tomar decisiones sobre sus propias vidas.

Por lo tanto, se puede identificar a partir de la variable tiempo, una asociación entre el desempeño de roles tradicionales de género en las relaciones familiares, donde se le asigna a la mujer el papel de productora y portadora de vida, las funciones para el mantenimiento de los hogares como lo son el trabajo doméstico y el de cuido. Mientras que los hombres, sobre todo si son solteros, no tienen dicha obligación. Como afirma Sasse (2003), se "[...] enmascara nuevamente el mito del igualitarismo marital y de la emancipación femenina a través del empleo, mientras mantiene intactas las estructuras patriarcales del hogar y del trabajo" (p.19).

Por otra parte, es interesante analizar la relación de parentesco de la persona "nini" con la persona jefa de hogar. En el primer rango de edad (12 a 24 años) las mujeres son en su mayoría hijas (50,09\%); seguido de cónyuges $(24,75 \%)$; otros familiares y no familiares $(20,95)$ y por último, jefaturas de hogar $(4,19 \%)$. En los hombres el $91,98 \%$ son hijos, y el $8,02 \%$ otros familiares o no familiares.

Tabla 5

EUT-GAM. Personas "ninis" de 12 a 24 años de edad, por sexo y relación de parentesco (2011)

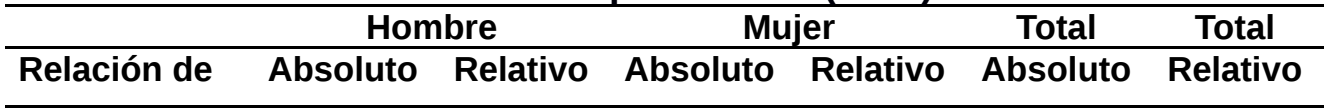




\begin{tabular}{lcccccc}
\hline parentesco & \multicolumn{1}{l}{} & & & & & \\
\hline Jefatura & 0 & 0 & 829 & 4,19 & 829 & 3,18 \\
\hline Cónyuge & 0 & 0 & 4897 & 24,75 & 4897 & 18,76 \\
\hline Hijos e hijas & 5812 & 91,98 & 9909 & 50,09 & 15721 & 60,24 \\
\hline $\begin{array}{l}\text { Otros } \\
\text { familiares y } \\
\text { no familiares }\end{array}$ & 507 & 8,02 & 4145 & 20,95 & 4652 & 17,82 \\
\hline
\end{tabular}

Fuente: Elaboración propia a partir de datos de la Encuesta sobre uso del tiempo del Gran Área Metropolitana (EUT-GAM), 2011.

Los datos de la tabla 5 revelan varias aristas para analizar alrededor del tema de las personas "ninis". Por ejemplo, Martínez Franzoni \& Voorend (2009), analizando datos de uso del tiempo en Costa Rica, afirman por ejemplo que cuando las mujeres adultas no están en el hogar, "[...] son las niñas, y no los hombres adultos, quienes asumen estas tareas. Por eso, cuanto mayor es el número de mujeres de 13 años o más presentes en el hogar, menor es el tiempo que le destinan los hombres al TDNR" (154). Asimismo, la cifra de cónyuge revela, nuevamente, la continuación en la tradicional división sexual del trabajo.

Por otro lado, llama la atención el alto porcentaje de mujeres en la categoría "otros familiares y no familiares" dentro de este rango de edad. De acuerdo con los resultados de un módulo especial sobre trabajo infantil y adolescente aplicado a la Encuesta Nacional de Hogares (ENAHO), se indicó que alrededor del 4\% de niños, niñas y adolescentes entre 5 y 17 años se encontraban en situación de trabajo infantil y trabajo adolescente peligroso (OIT \& MTSS, 2012). En este mismo estudio, se determinó que el 73,4\% de niños y niñas de 15 a 17 años realizan tareas domésticas. La tasa de participación en trabajo doméstico de niños y adolescentes es de 58,8\%; la de las mujeres es de un 78,5\% para ambos sexos, "[...] la participación en tareas domésticas en el propio hogar aumenta con la edad, pero tal aumento es bastante más intenso en el caso de las mujeres. Es decir, la participación de las mujeres es mayor en todos los grupos de edad, y dicha diferencia aumenta conforme se avanza en edad" (OIT \& MTSS, 2012, p. 48). Para Costa Rica, el umbral para considerar una actividad como trabajo peligroso en la niñez y adolescencia, son los trabajos de más de 14 horas semanales (OIT \& MTSS, 2012).

Por lo tanto, nuevamente se confirma la recurrencia en la división sexual del trabajo. Además, son las mujeres en general, no solo las que son cónyuges, quienes están produciendo el trabajo de cuidado y doméstico en la sociedad costarricense. Con lo cual, desde niñas se les postergan las oportunidades para el acceso a una ciudadanía digna, como las que pregonaba el feminismo sufragista y por el derecho a la educación. En ese mismo sentido, 
hay una subyugación en las relaciones familiares que hacen que las mujeres estén más abocadas a realizar trabajos de cuidado y doméstico.

Por último, se debe ahondar en investigaciones que den cuenta en mayor profundidad sobre las jefaturas de hogar de mujeres de 14 a 24 años, ya que este es un tema de feminización de la pobreza de hogares monoparentales con jefatura femenina. La brecha es aún más angustiante cuando se analiza con la variable edad.

Por último, en la tabla 6 se muestra el rango de 25 a 35 años de edad con relación al parentesco con la jefatura de hogar. Se identifica un alto porcentaje de mujeres cónyuge $(55,79 \%)$, jefas de hogar $(25,17 \%)$, hijas $(16,01 \%)$ y $3,04 \%$ de otros familiares o no familiares. El 100 por ciento de los hombres para este rango de edad fueron identificados como jefes de hogar.

Tabla 6

EUT-GAM. Personas "ninis" de 25 a 35 años de edad, por sexo y relación de parentesco (2011)

\begin{tabular}{lcccccc}
\hline $\begin{array}{l}\text { Relación de } \\
\text { parentesco }\end{array}$ & \multicolumn{2}{c}{ Hombre } & \multicolumn{2}{c}{ Mujer } & \multicolumn{2}{c}{ Total } \\
\cline { 2 - 7 } & $\begin{array}{c}\text { Absolut } \\
\mathbf{0}\end{array}$ & Relativo & $\begin{array}{c}\text { Absolut } \\
\mathbf{0}\end{array}$ & Relativo & Absoluto & Relativo \\
\hline Jefatura & 826 & 100 & 7005 & 25,17 & 7831 & 27,32 \\
\hline Cónyuge & 0 & 0 & 15528 & 55,79 & 15528 & 54,18 \\
\hline Hijos e hijas & 0 & 0 & 4455 & 16,01 & 4455 & 15,54 \\
\hline $\begin{array}{l}\text { Otros } \\
\text { familiares }\end{array}$ & 0 & 0 & 846 & 3,04 & 846 & 2,95 \\
$\begin{array}{l}\text { y no } \\
\text { familiares }\end{array}$ & & & & & & \\
\hline Total & 826 & 100 & 27834 & 100 & 28660 & 100 \\
\hline
\end{tabular}

Fuente: Elaboración propia a partir de datos de la Encuesta sobre uso del tiempo del Gran Área Metropolitana (EUT-GAM), 2011.

En esta tabla, se puede identificar nuevamente la división sexual del trabajo puesto que el rubro más alto corresponde a las mujeres cónyuges de la jefatura de hogar con un 55,79\%. Tanto las cónyuges como las jefas de hogar desempeñan un rol tradicional de género, al estar dedicadas a las labores domésticas y de cuidado. Sin embargo, en el caso de los cónyuges, es claro también el papel tradicional del hombre quién es el que sale a trabajar para proveer el sustento del hogar. En las jefaturas femeninas, son ellas quienes cumplen dobles jornadas, o recurren a otras mujeres jóvenes en los hogares para solventar el trabajo de cuido y trabajo doméstico.

Es necesario realizar estudios más profundos sobre las jefaturas de hogar femeninas de hogares monoparentales, puesto que se evidencia que dichos 
hogares están asociados a altos niveles de pobreza, y tal vez es ahí donde se genera el trabajo peligroso de niños, niñas y adolescentes a lo interno de los hogares. Por ejemplo, en la Encuesta Nacional de Ingresos y Gastos de los Hogares del 2013 se identificaron, a nivel nacional, un 35,9\% de hogares con jefatura femenina, y para la zona urbana se incrementa a un 37,9\%. Asimismo, de acuerdo con la Encuesta de Hogares de propósitos múltiples del 2013, del total de hogares pobres el 40,1\% tienen jefaturas femeninas; del total de hogares en pobreza no extrema el $38,7 \%$ tienen jefatura femenina y del total de hogares en pobreza extrema el $43,3 \%$ son liderados por jefaturas femeninas.

Por último, también se deben ampliar las investigaciones en miras de las actividades efectuadas por los hombres "ninis", puesto que si no lo están invirtiendo mayoritariamente en trabajo doméstico en la casa, se deben ampliar las investigaciones para dar cuenta de lo que realmente sucede con estas personas y en qué actividades están involucrados.

\section{Conclusiones}

A partir de la EUT-GAM 2011, se identificaron 54759 personas entre 12 y 35 años que reportan no trabajar remuneradamente y tampoco estudiar. La gran mayoría son mujeres (87\%) y dentro de este porcentaje el $64 \%$ están casadas o viven en unión libre.

Asimismo, se distinguieron dos rangos de edad poblacional: el primero de ellos corresponde a personas entre 12 a 24 años, donde las mujeres representan el $75,8 \%$ y $24,2 \%$ son hombres. De la población total en este rango, el 50,09\% de las mujeres son hijas de la persona jefa de hogar, seguido de un $24,5 \%$ de mujeres cónyuges.

En cuanto al rango que abarca una población de 25 a 35 años de edad, el $97,1 \%$ son mujeres, de las cuales el $55,79 \%$ son cónyuges de la jefatura de hogar y, por otro lado, llama la atención, la existencia de un 25,17\% de mujeres que no reportan trabajar remuneradamente o estudiar pero que además son jefas de hogar.

Por lo tanto, a partir de la caracterización de estas personas de acuerdo con su edad y parentesco en relación con la jefatura de hogar, se puede observar que los resultados dan cuenta de que existe una clara división sexual del trabajo, basada en el ejercicio de roles tradicionales asociados al género, en donde se le atribuye el trabajo doméstico y de cuido a las mujeres dentro del núcleo tradicional familiar, que corresponde al hogar biparental con el hombre como proveedor económico. 
Se puede concluir que de acuerdo con los datos obtenidos en la encuesta de uso del tiempo de 2011 para la GAM sobre la población considerada como "nini", especialmente en el rango de edad de 25 a 35 años, se sigue reproduciendo la lógica patriarcal de la tradicional división sexual del trabajo; en la cual, los hombres se vinculan con el espacio público y, en el espacio privado, se encuentran las mujeres. Lo anterior no significa que existe una falta de reconocimiento para las mujeres dentro de espacios importantes en la esfera pública, pero si implica que todavía no es de forma igualitaria ni en su mayoría.

Desde la primera mitad del siglo $X X$, los movimientos de mujeres en el mundo reivindican el derecho al ejercicio de una ciudadanía equiparable a la de los hombres, en tanto el acceso a derechos como la educación, la propiedad, el trabajo remunerado o al sufragio. A pesar de estas reivindicaciones logradas desde hace ya varias décadas, se puede constatar con los datos antes presentados, que todavía en la sociedad costarricense conviven mujeres con menos acceso y menos derechos a la ciudadanía que otras.

La autonomía no es equiparable para todas, y si se compara con los hombres es todavía menor. Este fenómeno se mantiene a partir de los discursos religiosos, paternalistas y patriarcales que se forjan en las instituciones sociales, y que al mismo tiempo, se reproducen culturalmente en las prácticas cotidianas.

La asignación de roles de género constituidos culturalmente pero asociados fundamentalmente a las funciones biológicas de cada sexo, nos lleva a la reflexión que realiza Sullerot sobre ¿por qué tales trabajos efectuados por las mujeres son desvalorizados y no son reconocidos como trabajo? Al contrario de las actividades realizadas por los hombres solo que para el mercado. Sullerot nos demuestra que "[...] su actividad, al ser explicada por su naturaleza, no es ya una actividad libre, sino una función" (Sullerot, 1988, p. 28).

Pero la pregunta planteada desde el feminismo entonces es ¿por qué la diferencia sexual biológica produce desigualdad?, a lo que Lamas (1986) contesta,

Que la diferencia biológica, cualquiera que ésta sea (anatómica, bioquímica, etcétera), se interprete culturalmente como una diferencia sustantiva que marcará el destino de las personas con una moral diferenciada es el problema político que subyace a toda la discusión académica sobre las diferencias entre hombres y mujeres (p. 9). 
Por lo tanto, el trabajo doméstico y de los cuidados es desvalorizado por su asociación a la reproducción de la vida y, por lo tanto, es visto como función inherente a la naturaleza. Por esto, no se le reconoce con el mismo valor que el trabajo para el mercado considerado en las sociedades occidentales como "productivo". El trabajo de los cuidados y doméstico no es reconocido como tal dentro de la economía marginalista y tampoco existe el reconocimiento del mismo como trabajo inherente al mantenimiento y reproducción de las mismas sociedades (Carrasco, 2011).

Es por esto que las feministas se dan a la tarea de reflexionar sobre el valor del trabajo hecho por las mujeres, en referencia al uso del tiempo como indicador de medida del bienestar de las personas, puesto que el bienestar constituye la satisfacción de necesidades esenciales para la vida, las cuales deben ser satisfechas a partir del tiempo que disponen las personas para realizar los trabajos que se requieren para dicho fin (Durán, 2007). Sin embargo, en nuestras sociedades el valor de los trabajos utilizados para alcanzar el bienestar es asimétrico, puesto que unos están reconocidos en el mercado por medio del dinero, no obstante, otros no y por lo tanto su valor es desigual.

Este debate sobre el valor del trabajo conlleva a reflexionar sobre ¿cómo precisamos e incorporamos las definiciones que reproducen estructuras de dominación y discriminación? Entendiendo que la no incorporación dentro de los discursos sobre lo que es reconocido y no dentro de una sociedad, denota la exclusión que conlleva la omisión del ejercicio real de la autonomía como sujetos. Al mismo tiempo, excluye de las grandes narrativas societales a las mujeres que dedican su vida al cuido y bienestar de su familias, que es la base de la reproducción de la vida misma y por ende de la humanidad.

Es por esto, que las feministas radicales atacan el centro del patriarcado que son las relaciones asimétricas de poder, por el simple hecho de ser mujeres. En este sentido, reconocer que "lo personal es político" es estar consciente que no solo las prácticas que pasan en lo público, en lo que se refiera a acceso a la ciudadanía, están impregnadas de ideología patriarcal. Es así que, dentro de la reproducción de la vida en la esfera privada, se generan relaciones desiguales de poder en las prácticas cotidianas dentro de los hogares. Estas prácticas cotidianas reproducen, por tanto, el sistema patriarcal, el cual le sirve al mismo tiempo al sistema capitalista para crear capital.

Desde una perspectiva marxista, se entiende que el trabajo se produce cuando realizamos ciertas actividades de índole creativa, las cuales transforman la naturaleza para poder ser apropiada y aprovechada para nuestro propio bienestar, por lo cual se define como una actividad transformadora. En ese sentido, el trabajo es la transformación de la naturaleza a manos del ser humano, es decir, una naturaleza labrada y, por 
tanto, transformada. Esta concepción sobre el trabajo deviene desde el criticismo de Kant, los pragmáticos y los marxistas (Sullerot, 1988).

En ese sentido, y como Federici (2013) ha expuesto, es necesario empezar a ver el trabajo no remunerado como una actividad transformadora, puesto que es este el que se ocupa por el trabajo de mantener la vida, en términos de salud, higiene, afectos y cariño. Las mujeres han realizado actividades de intercambio de servicios para mantener y reproducir la vida y el bienestar generalizado de sus familias: preparando la comida, tejiendo el vestido, haciendo crecer la huerta, cuidando los animales, limpiando el hogar, cuidando a niños y niñas, enfermos, adultos mayores y, por tanto, ¿no son estas actividades transformadoras de la naturaleza? (Sullerot, 1988).

También, lo señala McMurty (1999) de la siguiente manera,

El factor liberador que emerge del Tercer Mundo es la fuerza de las mujeres no asalariadas quienes aún no se han visto desconectadas de la economía vital por medio del empleo. Ellas sirven a la vida no a la producción de mercancías. Son la oculta columna vertebral de la economía mundial y el salario equivalente a sus vidas de trabajo se estima en 16 billones de dólares (p. 248).

Las mujeres han realizado estas tareas para quienes habitan en el hogar, es decir, en el ámbito privado y, por lo tanto, no existe un intercambio económico en esta relación. Al mismo tiempo, desde la Modernidad se sentaron las bases para que el trabajo doméstico y de los cuidados sea visto como función de las mujeres, y no como trabajo productivo, con lo cual se consolidó una asimetría entre el valor del trabajo no remunerado y el remunerado.

Al no haber intercambio monetario, el valor del trabajo decrece de tal forma, que no es considerado como tal, y por el contrario, es invisibilizado desde la economía formal. Entonces, al invisibilizar este trabajo, se discrimina a las mujeres y sus condiciones particulares de vida, en tanto, que no se valora las actividades que ellas realizan, sometiéndolas a tareas de nutrición y cuidado de forma cíclica (Amorós, 1994), sin que estas puedan acceder de manera autónoma al ejercicio de ciudadanías democráticas equivalentes a las de sus pares hombres.

No obstante, desde la economía feminista se esfuerzan para convertir lo invisible en visible. Por lo tanto, las encuestas de uso del tiempo son una estrategia de visibilización y reconocimiento del trabajo que las mujeres mayoritariamente realizan para cuidar y mantener vivas a las personas con las que habitan. 
Por consiguiente, se han ampliado alrededor del mundo iniciativas de encuestas de uso del tiempo cuyo objetivo radica, justamente, "[...] en las actividades mal conocidas y no reguladas, a las que grupos sociales emergentes se vinculan con intensidad por relaciones de aprecio o de rechazo" (Durán, 2011, p. 5). Asimismo, se desarrollan las cuentas satélites de trabajo no remunerado como,

Ejercicios conceptualmente complicados, porque tratan de ampliar los modos de interpretar un fenómeno a partir de marcos ya consolidados, para dar cabida a aspectos hasta entonces poco conocidos o descuidados. Se pretende mantener el marco antiguo incorporando el nuevo, y por eso se llaman cuentas satélite, porque giran en torno a una cuenta convencional sin amenazarla, pero haciéndose presentes como alternativa en zona de observación y espera (Durán, 2007, pp. 25-26).

El artículo demuestra a partir de los datos recopilados en la EUT-GAM 2011, que son en la mayoría mujeres las consideradas como "nini" (ni estudia, ni trabaja). Sin embargo, estas mujeres distan de ser improductivas 0 desocupadas ya que en la mayoría de los casos dedican más de 50 horas semanales al trabajo reproductivo y de cuido en sus hogares.

Por lo tanto, estas mujeres no son "ninis", sin embargo, este término sí puede aplicarse para los hombres que realizan poco o muy poco trabajo doméstico y de cuido. Analizar entonces, qué están haciendo estos "ninis" hombres con su tiempo y en qué lo están ocupando, son investigaciones pendientes en el país.

De esta forma, el no reconocimiento como trabajo de las actividades que realizan sobre todo las mujeres dentro de los hogares, reproduce los estereotipos de género, los cuales impiden que se registren y valoren sus aportes a la economía y al bienestar general de la población costarricense.

Es necesario promover y efectuar investigaciones utilizando el tiempo como variable de medida, puesto que ayuda a identificar formas de discriminación y brechas de género, por medio del "uso" o "intercambio" que tienen las personas sobre su propio tiempo. De esta manera, con la EUT-GAM 2011, se evidenciaron las altas jornadas de trabajo que tienen las mujeres jóvenes que reconocen no estudiar ni trabajar para el mercado, lo cual conlleva a identificar otros problemas de estas mujeres en relación con el acceso a un sustento económico, posibilidades reales de inserción a la educación y, en general, cuestiones de ejercicio de derechos básicos en una democracia, lo cual nos induce a preguntar: ¿cuál es el reconocimiento real que tienen estas 
mujeres en el ámbito público que es el espacio donde se entreteje el ejercicio de las ciudadanías democráticas modernas? Y lo que es más preocupante, ¿padecen estas mujeres costarricenses atisbos de reivindicaciones que las mujeres desde mediados del siglo XX en Costa Rica alcanzaron? Asimismo, el patriarcado sigue articulando las relaciones de poder asimétricas dentro de los hogares por medio de la división sexual del trabajo, los roles tradicionales de género y las prácticas culturales que mantienen y reproducen esta lógica dentro de las sociedades.

En conclusión, se demuestra que Costa Rica no escapa de esta reproducción asimétrica del bienestar para hombres y mujeres. Los cuestionamientos pasan por analizar el tipo de regímenes de bienestar y órdenes de género que la sociedad reproduce (Martínez Franzoni \& Voorend, 2009). La discusión debe pasar por la sociedad, el Estado y el mercado; si se sigue promoviendo una lógica de protección social, o si se mueve la organización social en una lógica del cuidado, donde el papel de la persona cuidadora es igual de importante que la persona cuidada, donde el cuidado es considerado como un derecho universal y no como un factor de asistencial como muchos más (Esquivel, 2011).

\section{Bibliografía}

Aguirre, R.; Ferrari, F. (2013). Las encuestas sobre uso del tiempo y trabajo no remunerado en América Latina y el Caribe. Caminos recorridos y desafíos hacia el futuro. En Serie Asuntos de Género (pp.1-94). Santiago: CEPAL.

Amorós, C. (1994). Espacio público, espacio privado y definiciones ideológicas de 'lo masculino' y 'lo femenino'. En C. Amorós (Ed.), Feminismo, igualdad y diferencia (pp. 23-52). México: UNAM, PUEG.

Anderson, J. (2002). Familias, maternalismo y justicia de género: Dilemas de la política social. Seminario: Programación estratégica, análisis prospectivo y tecnologías para el cambio organizacional; la gestión y evaluación de políticas de equidad de género.

Barrantes, A. (2013, marzo 21). Jóvenes ninis vagan entre falta de oportunidades y desinterés. La Nación. Recuperado de http://www.nacion.com/archivo/Jovenes-ninis-vagan-oportunidadesdesinteres_0_1330667061.html/ [Consulta 3 de feb. 2013].

Benhabib, S. (1990). El otro generalizado y el otro concreto: la controversia Kolhberg Gilligan y la teoría feminista. En S. Benhabibi, \& D. Cornell (Eds.), Teoría feminista y teoría crítica (pp 137-150). Valencia: Alfons el Magnanim. 
Bonderías, C.; Carrasco, C., \& Torns, T. (2011). Introducción. El trabajo de cuidados: antecedentes históricos y debates actuales. En C, Bonderías; C, Carrasco \& Torns (Eds.), El trabajo de los cuidados. Historia, teoría y políticas (pp. 13-80). Madrid: Los libros de la Catarata.

Carrasco, C. (2011). La economía del cuidado: planteamiento actual y desafíos pendientes. En Revista de Economía Crítica (pp.205-225), Barcelona: UBA.

Castro Valverde, C. (2013). Informe Final Desempeño de la educación general básica y el ciclo diversificado en Costa Rica (IV Informe de la Educación). San José: Programa Estado de la Nación. [pdf]. Recuperado de http://wwhw.estadonacion.or.cr/files/biblioteca_virtual/educacion/004/ca stro_desempeno-ed-basica-y-diversificado.pdf/] [Consulta 25 ene. 2016].

Chung, Y. (2012). Educación con más arte igual menos «ninis». Eka La Revista Empresarial. Recuperado de http://www.ekaenlinea.com/blogeducacion-con-mas-arte-menos-ninis/ [Consulta 3 feb. 2016].

Cobo, R.; Ortega-Serrano, R.; Leyra-Fatou, B., \& Aparacio-García, M. (2009). Cuadernos de género: políticas y acciones de género: Materiales de formación. Madrid: Instituto Complutense de Estudios Internacionales D.L.

Consejo Nacional de la Política Pública de la Persona Joven y Fondo de Población de las Naciones Unidas. (2010). Política Pública de la Persona Joven y su Plan de Acción. San José: Fondo de Población de las Naciones Unidas.

Contraloría General de la República de Costa Rica. (2014). Informe de la auditoría sobre las acciones de política pública respecto a la población joven que no estudia ni trabaja (No. DFOE-SOC-IF-15-2014). [pdf]: Recuperado https://cgrfiles.cgr.go.cr/publico/docsweb/ninis/docs/DFOE-SOC-IF-152014.pdf/ [Consulta 20 ene. 2016].

Diario Extra (2016, 26 de enero). Costa Rica: El efecto «ninis»? Recuperado de http://www.entornointeligente.com/articulo/7767663/COSTA-RICAEl-efectoninis-26012016/ [Consulta 3 feb. 2016].

Durán, M. A. (2005). La cuenta satélite del trabajo no remunerado en la comunidad de Madrid. Madrid: Dirección General de la Mujer.

Durán, M. A. (2007). El valor del tiempo ¿cuántas horas te faltan al día? Madrid: Espasa Calpe S. A. 
Durán, M. A. (2011, junio). El tiempo como campo de políticas públicas. Seminario internacional. Políticas de tiempo, tiempo de las políticas. Cuadragésima sexta reunión de la Mesa Directiva de la Conferencia Regional sobre la Mujer de América Latina y el Caribe.

Esquivel, V. (2011) La economía del cuidado en América Latina: poniendo a los cuidados en el centro de la agenda. El Salvador: PNUD.

Federici, S. (2013). Revolución en punto cero trabajo doméstico, reproducción y luchas feministas. Madrid: Traficantes de sueños.

Friedan, B. (2009). La mística de la feminidad. Madrid: Universidad de Valencia.

Gutiérrez-García, R. A.; Martínez-Martínez, K. I.; Pacheco-Trejo, A. Y. (2014). Los jóvenes que no estudian ni trabajan en México. Enseñanza e Investigación en Psicología, 19. Recuperado de http://www.redalyc.org/articulo.oa?id=29238007007/

Instituto Nacional de Estadísticas y Censos. (2011a). X Censo Nacional de Población y VI de Vivienda: Resultados Generales. San José, Costa Rica: INEC.

Instituto Nacional de Estadísticas y Censos. (2011b). X Censo Nacional de Población y VI de Vivienda 2011.Características económicas. San José, Costa Rica: INEC.

Instituto Nacional de las Mujeres; Universidad Nacional. Instituto de Estudios en Población, e Instituto Nacional de Estadísticas y Censos. (2012). Encuesta de uso del tiempo en la Gran Área Metropolitana 2011: Una mirada cuantitativa del trabajo invisible de las mujeres. San José: INAMU; UNA-IDESPO; INEC. [pdf]. Recuperado de http://www.inec.go.cr/A/MI/Publicaciones/Publicaciones \%20Especiales/Publicaciones/09.\%20Principales\%20resultados\%20de \%20la\%20Encuesta\%20de\%20Uso\%20del\%20Tiempo\%20de\%20la \%20GAM-2011.pdf

Kant, I. (1784). Respuesta a la pregunta: ¿Qué es la llustración? Königsberg. Recuperado de http://www.google.co.cr/url? $\mathrm{sa}=\mathrm{t} \& \mathrm{rct}=\mathrm{j} \& \mathrm{q}=\& \mathrm{esrc}=\mathrm{s} \&$ source $=$ web $\& \mathrm{~cd}=1 \& \mathrm{ved}=0 \mathrm{CCOQFjAA} \&$ url=http \%3A\%2F\%2Fwww.ginersg.org\%2FFILOSOFIA\%2Ftextos $\% 2$ FKANT.Respuesta\%2520a\%2520la \%2520pregunta.pdf\&ei=|x3CUODuEZPi9gTdOYDYDg\&usg=AFQjCNE XgUpVI8fkOUKLlupwkHCIX4jVxA\&sig2=rYOuMTLG41KODhYtUrV oww/ [Consulta 12 jun. 2012]. 
Lamas, M. (1986). La construcción cultural de la diferencia sexual. Nueva antropología. Estudios sobre la mujer: problemas teóricos. Iztapalapa: CONACYT/UAM.

Costa Rica, Asamblea Legislativa. (2002). Ley General de la Persona Joven o Ley $N^{\circ}$ 8261. Costa Rica: autor.

Martínez-Franzoni, J. \& Voorend, K. (2009). Sistemas de patriarcado y regímenes de bienestar en América Latina. Madrid: Fundación Carolina.

Mazzei, A. (2012, octubre). Caracterización de la población Nini: Ni estudia ni trabaja. Simposio Costa Rica a la luz del Censo 2011.

Millet, K. (1995). La política sexual. (Col. Feminismos). Madrid: Ed. Cátedra.

McMurtry, J. (1999). The Cancer Stage of Capitalism. London: Pluto Press.

Organización Internacional del Trabajo. (2014). Trabajo decente y juventud en América Latina 2010. Perú: OIT.

Organización Internacional del Trabajo \& Ministerio de Trabajo y Seguridad Social (2012). Magnitud y características del trabajo infantil $y$ adolescente en Costa Rica - Informe 2011. San José, Costa Rica: OIT.

Repretel. (2015, septiembre 16). El aumento del número de «ninis» preocupa. El país no tiene cómo atender a los jóvenes que no estudian ni trabajan. Noticias Repretel. Recuperado de http://www.repretel.com/actualidad/el-aumento-del-numero-de-ninispreocupa-2348/ [Consulta 3 feb. 2016].

Rodríguez-Enríquez, C. (2005, septiembre). Economía del cuidado y política económica: Una aproximación a sus interrelaciones. Panel: Política de Protección social, economía del cuidado y equidad de género. Trigésima octava reunión de la Mesa Directiva de la Conferencia Regional sobre la Mujer de América Latina y el Caribe.

Sandoval-Carvajal, I. \& González-Vega, L. (2015). Estimación del valor económico del trabajo no remunerado en Costa Rica. Resultados e ilustración metodológica. En Estudios Demográficos y Urbanos (pp. 691-724). Distrito Federal: El Colegio de México, A.C.

Sassen, S. (2003). Contrageografías de la globalización. Género y ciudadanía en los circuitos transfonterizos. Madrid: Traficantes de sueños.

Scott, J. (2008). Género e Historia. Ciudad de México: Fondo de Cultura Económica, Universidad Autónoma de México. 
Sullerot, E. (1988). Historia y sociología del trabajo femenino. Barcelona: Ediciones $62 \mathrm{~S}$. A.

Téllez-Velasco, D. (2011). Jóvenes nini y profesionistas titi: la estratificación letrada del desempleo. El Cotidiano, 169, 83-96.

Valcárcel, A. (2001). La memoria colectiva y los retos del feminismo. Mujer y Desarrollo (pp.1-34). Santiago: CEPAL.

Zúñiga-Villalobos, P., \& Begurí-Pagés, M. (2012). Fascículo №1. Características demográficas del cantón de San José con comparaciones. Censo Nacional de población y vivienda 2011. Observatorio municipal dirección de planificación y evaluación. [pdf] Recuperado de https://www.msj.go.cr/informacion_ciudadana/SiteAssets/FASC \%C3\%8DCULO\%20No\%201\%20CARACTER\%C3\%8DSTICAS \%20DEMOGR\%C3\%81FICAS.pdf/ [Consulta 12 dic. 2015]. 